\title{
MIRADAS SOBRE LA MIGRACIÓN ARGENTINA EN ESPAÑA: FUENTES ORALES, PERIODÍSTICAS Y CINEMATOGRÁFICAS
}

\author{
Perspectives on Argentine Migration to Spain: Oral, Journal and Film Sources
}

Susana SCHMIDT

Universidad de Salamanca

E-mail: schmidt@usal.es

Fecha de recepción: 22-01-2010

Fecha de aceptación: 29-01-2010

\begin{abstract}
RESUMEN: En esta contribución se retoma el tema de nuestra investigación doctoral -las migraciones recientes de argentinos a España- para compartir algunas reflexiones de orden teórico-metodológico. Hacemos referencia a la conceptualización de los "espacios sociales transnacionales", un enfoque que nos permite considerar la migración en su doble dimensión origen/destino y que resulta especialmente útil al momento de abordar la relación entre migración y creación de vínculos sociales y culturales dentro de ese espacio hispanoargentino o argentino-español. Del mismo modo, la perspectiva de espacios transnacionales permite poner en diálogo a diversos grupos de actores sociales que están involucrados en el fenómeno: los propios migrantes, a cuyas trayectorias vitales nos acercamos mediante la utilización de fuentes orales; la sociedad expulsora y la sociedad receptora, cuyos imaginarios colectivos tratamos de analizar a través de fuentes periodísticas; los productores de cine, cuyos relatos de migración abordamos a través de distintas películas de ficción; y, cómo no, los historiadores y demás científicos sociales que estudian estas migraciones.

Palabras clave: migraciones internacionales, argentinos, España, metodología, fuentes orales, representaciones sociales

RESUMEN: This contribution takes up our doctoral research -Argentine migration to Spain- to share some theoretical-methodological considerations. We refer to the conceptualization of "transnational social spaces," an approach that allows us to consider migration in its double dimension origin/destination and is particularly useful to thing the relationship
\end{abstract}


between migration and creation of social and cultural ties in the Hispano-Argentine or Argentine-Spanish space. Similarly, the transnational spaces approach allows to put in dialog diverse social groups involved in the phenomenon: the migrants themselves, whose life stories are analysed by using oral sources; the society of origin and the host society, analysing collective image through journal sources; the filmmakers, whose migration stories we discuss migration through various fiction films; and, of course, historians and other social scientists who study these migrations.

Keywords: International Migration, Argentines, Spain, Methodology, Oral History, Social Representations

El movimiento migratorio de argentinos que vienen a España con la intención de encontrar un nuevo espacio en el cual trabajar y desarrollar sus vidas, si bien experimenta un crecimiento sin precedentes en los años que rodean la crisis económica, social y política de 2001 en Argentina, no es un fenómeno nuevo. "Poniendo títulos fáciles, para situarnos, podemos hablar de tres flujos diferenciados: el del exilio (fines de los '70), el de la hiperinflación de la época de Alfonsín (segunda mitad de los '80) y el del corralito (el actual). Y esto tiene unas consecuencias importantes: la gente viene del mismo país pero procede de momentos históricos distintos, de situaciones sociales y de trayectorias vitales diferentes. Y eso tiene consecuencias para el asociacionismo, para el establecimiento de redes sociales, etcétera..." (Actis, 2005: 143).

Es a partir del año 2000 cuando se produce un incremento sin precedentes del número de migrantes argentinos en España: en el plazo de tres años llegaron más personas desde Argentina ${ }^{1}$ que las que se habían establecido a lo largo de las dos décadas. Mediada la primera década del siglo XXI hay algo más de un cuarto de millón de argentinos en España (Actis y Esteban, 2007: 230).

Unas palabras acerca de la composición del stock de población de origen argentino que reside actualmente en España, es decir, después de la llegada del éxodo masivo del corralito. En cuanto a las características demográficas, la tendencia al equilibrio en su composición por sexo se mantiene, pero con una cierta masculinización, lo que podría ser explicado a partir de la mayor tasa de desempleo masculino en Argentina durante la crisis. La llegada masiva de población adulta-joven (franja de edad entre los 20 y los 44 años) produce un rejuvenecimiento del conjunto. Igualmente, el incremento de la población menor de 20 años apunta a la migración de grupos familiares (que incluyen padres e hijos menores de edad). El crecimiento de otros segmentos de edad, entre ellos el de mayores de 65 años, refleja la extensión de la crisis. "En síntesis, los datos nos muestran una emigración que 
afectó a personas de ambos sexos y de todas las edades, aunque se concentró especialmente en los hombres y entre los menores de 45 años" (Actis y Esteban, 2007: 232-234).

Relativo a los orígenes sociales, la nueva oleada deja en entredicho la caracterización de la migración desde Argentina como predominantemente clasemediera, dando lugar a una diversificación de las procedencias. Aunque el censo de 2001 revela que existía un segmento significativo de argentinos con formación superior, el importante volumen de migrantes llegados desde Argentina que, según la Estadística de Variaciones Residenciales de 2000, no supera los estudios primarios, muestra que la migración reciente presenta perfiles diferenciados en función de su nivel de formación académica. Según la Encuesta de Población Activa de 2005, el perfil formativo de los argentinos con 16 o más años es superior al de la población española y sólo superada por los extranjeros procedentes de la Unión Europea. Sin embargo los datos de la propia EPA sugieren que el nivel de estudios de los migrantes con más años de residencia en España es mayor que el de los llegados más recientemente (Actis y Esteban, 2007: 234-237).

$\mathrm{El}$ asentamiento espacial de los argentinos se dispersa por toda la geografía española. A principios del siglo XXI, las áreas que más aumentaron el número de nacidos en Argentina son Comunidad Valenciana, Andalucía, Canarias y Baleares, Cataluña y Castilla-La Mancha. Cataluña ocupa el primer puesto, seguido a distancia por Madrid, alcanzado prácticamente por Andalucía y Comunidad Valenciana; Baleares y Canarias, pasan a ocupar el cuarto lugar, sobrepasando a Galicia. Se mantiene el flujo hacia provincias costeras (incorporando ahora a Tarragona y Girona) y se inicia otro, de "difusión" hacia zonas del interior, al tiempo que Madrid continuó perdiendo importancia relativa (confirmando la tendencia iniciada en la segunda mitad de los noventa). Por municipios, los mayores incrementos y concentración de la población llegada recientemente desde Argentina se han registrado en municipios costeros-turísticos. "Por tanto, cabría sintetizar los destinos elegidos por la inmigración argentina en cuatro tipos diferenciados: (1) metrópolis globales (Madrid y Barcelona) y sus periferias; (2) zonas turísticas, de costa; (3) capitales gallegas; y (4) zonas del interior" (Actis y Esteban, 2007: 237-240).

La elevada tasa de actividad de los argentinos confirma el fortísimo componente laboral de la última oleada migratoria. También se constata un elevado porcentaje de desocupados argentinos. "Ambas cuestiones (actividad y desocupación) sitúan a los argentinos en el campo de los inmigrantes económicos extracomunitarios, que se diferencia claramente del perfil de la población española y la procedente de la Unión Europea." Los perfiles laborales de los migrantes argentinos en España son diferenciados: aunque el grueso ha conseguido eludir algunos de los típicos "empleos para inmigrantes" (construcción, servicio doméstico, agricultura), están muy presentes en otros 
(hostelería, comercio), pero también se extienden hacia ocupaciones de mayor calidad o prestigio (intermediación inmobiliaria, financiera, industria). El perfil de los argentinos apunta a una "dualidad" entre los grupos más favorecidos y los más perjudicados por su inserción laboral. Mientras la proporción de técnicos acerca el perfil a los españoles y europeos comunitarios, la de trabajadores de la hostelería y el comercio lo aproxima al de otros inmigrantes latinoamericanos y asiáticos. De modo que, a pesar de la situación global relativamente favorable, existe un segmento de argentinos sometidos a condiciones de trabajo precario y mal remunerado. Además, si tenemos en cuenta el elevado porcentaje de "sin papeles" que parece subsistir hasta la fecha, es probable que parte de este empleo se desarrolle "en negro", sin ningún tipo de derechos laborales y sociales (Actis y Esteban, 2007: 240243).

Estas serían, en resumidas cuentas, las coordenadas sociológicas del colectivo argentino radicado en España durante esos años (o en los inmediatamente previos) en los que nosotros iniciábamos nuestra investigación. Tratando de reconstruir con qué intereses e inquietudes nos acercábamos al tema de la migración argentina, entendemos que son tres los elementos que finalmente nos llevaron a la elección de nuestro camino teórico y metodológico. En primer lugar, buscábamos un acercamiento desde la historia a una cuestión que se encontraba en el presente, es decir, entender las migraciones actuales como proceso en el tiempo, en la línea de la Historia del Presente 2. Reconociendo el tiempo lento de las estructuras (Braudel, 1979) como factor esencial para entender las coyunturas, nos proponíamos un recorrido en el tiempo que partiera desde el acontecimiento mediático y alcanzara a la larga duración: del flujo de buidos del corralito a la historia de intercambios poblacionales dentro del sistema migratorio ${ }^{3}$ constituido por España y Argentina. Segundo, en una coyuntura en la que España se había convertido en país receptor de población migrante procedente del denominado Tercer Mundo es en este momento en el que aparece el interés por el tema de "la inmigración" en la sociedad en general y, de modo específico, en la comunidad científica, que orienta los estudios mayoritariamente hacia aspectos que tienen que ver con "los problemas" en el proceso de adaptación de los nuevos moradores-, nuestro deseo era poder considerar la doble dimensión emigratoria-inmigratoria, analizar la migración como fenómeno social complejo en el que es preciso tener en cuenta la sociedad de origen tanto como la de destino. Finalmente, nos interesaba especialmente indagar los vínculos que se generan entre estos dos espacios a raíz de los intercambios migratorios, lo que, traducido a la perspectiva de los propios migrantes, significaba preguntarse cómo gestionan ellos el vivir entre dos mundos.

En lo que sigue exponemos cómo se concretaron estos planteamientos en el marco teórico de espacios transnacionales y cómo se concretó la utili- 
zación de fuentes orales, periodísticas y fílmicas, además de, obviamente, bibliográficas.

\section{EL ENFOQUE DE ESPACIOS SOCIALES TRANSNACIONALES}

"Los espacios transestatales son lazos plurilocales de personas, redes, comunidades y organizaciones que existen cruzando las fronteras de varios Estados. Estos vínculos transestatales tienen una elevada densidad y frecuencia y sus formaciones más duraderas permanecen más allá de una generación. Estos lazos transestatales se caracterizan por circuitos de personas, mercancías, dinero, símbolos, ideas y prácticas culturales. El flujo de los elementos de intercambio como bienes y personas puede tener diversas intensidades. Para nuestro caso, que pone en relación migración interestatal y espacios sociales, tienen especial importancia las personas y los vínculos que estableen entre sí, a través de redes, organizaciones y comunidades” (Faist, 2000: $13)^{4}$.

Siguiendo esta definición del politólogo alemán Thomas Faist, los espacios sociales (Räume) que resultan de la migración interestatal no son territorios claramente demarcados sino:

"Espacio se refiere a las relaciones sociales y simbólicas de actores en y entre territorios o lugares. El concepto espacio, por lo tanto, no comporta únicamente atributos físicos. Engloba, igualmente, condiciones macroestructurales como lazos sociales o simbólicos entre personas y colectivos y actitudes subjetivas, valores y adscripciones de significado. Espacio y lugar se diferencian en tanto que espacio engloba distintos lugares territoriales junto con las relaciones implícitas. Es importante señalar que incluso en el caso de la migración, la expansión de los espacios sociales más allá de las fronteras puede producirse, en fases avanzadas, sin movilidad geográfica de personas. Por ejemplo, a través de procesos de comunicación, que a pesar de la distancia geográfica pueden indicar cercanía social" (Faist, 2000: 14-15).

Los actores transestatales, como por ejemplo los migrantes, movilizan capitales -económicos, humanos, sociales y simbólicos ${ }^{5}$ - que circulan en el espacio transestatal. En función del grado de formalización, por un lado, y de la perdurabilidad, por otro, Faist (2000: 17-38) elabora una tipología de estos espacios transestatales en la que resultan cuatro grupos:

Los "campos de contacto" (Kontaktfelder), además de caracterizarse por el desplazamiento de personas, son circuitos de intercambio de bienes y redes en los que se difunden ideas, prácticas culturales, informaciones, etcétera. Estos espacios de contacto, en cuya creación juegan un papel importante los medios de comunicación de masas, son la base para la acción de muchas personas que no necesariamente están coordinadas a través de organizaciones y comunidades. 


\begin{tabular}{|l|l|l|}
\hline \multicolumn{2}{|l|}{ Cuadro 1. Tipos de espacios transestatales } \\
\hline $\begin{array}{l}\text { Grado de } \\
\text { formalización } \\
\text { Duración } \\
\text { potencial }\end{array}$ & bajo (redes) & alto (organizaciones) \\
\hline corta & $\begin{array}{l}\text { Campos de contacto de bienes, personas, } \\
\text { informaciones y prácticas }\end{array}$ & Grupos pequeños (de parentesco) \\
\hline larga & Redes temáticas & $\begin{array}{l}\text { Comunidades (de aldea, religiosas, } \\
\text { diaspóricas, de frontera, grupos étnicos } \\
\text { extranjeros) y organizaciones (movimientos } \\
\text { sociales, empresas transnacionales) }\end{array}$ \\
\hline
\end{tabular}

Fuente: Faist (2000: 19).

Los "pequeños grupos transestatales" (transstaatliche Kleingruppen), como familias o sistemas de parentesco, tienen un elevado grado de institucionalización y son característicos de los migrantes de primera generación; más allá de ésta es más difícil que se mantengan los lazos. Se basan en la reciprocidad y la solidaridad, que se traduce en prácticas como por ejemplo el envío de remesas. Sólo se puede hablar de hogares o familias transestatales cuando conservan la conciencia de pertenecer a un lugar compartido, aunque son muy pocos los casos en que los migrantes se mueven de un sitio a otro de manera prolongada.

Las "redes temáticas" (themenzentrierte Netzwerke) son tejidos poco institucionalizados en los que circulan bienes, ideas, informaciones y personas. Puede tratarse de empresarios en el país de origen y de destino que se unen para cooperar en un determinado sector económico, como por ejemplo la producción textil o la importación de alimentos, aprovechando los contactos y el conocimiento del lugar. En el ámbito de las organizaciones no gubernamentales hay también redes de personas que se unen para operar a través de las fronteras: tal es el caso de los activistas políticos que comparten valores por los que luchan, como los derechos humanos o el medio ambiente. Las relaciones en el marco Norte - Sur, remiten a una larga historia de vínculos que pueden ser la base sobre la que se consolidan los sistemas migratorios o se crean otros nuevos.

Al tener un elevado grado de institucionalización, las "comunidades transestatales" (transstaatliche Gemeinschaften) y "organizaciones transestatales" (transstaatliche Organisationen) son potencialmente muy longevas. Aunque en 
ocasiones se superponen (como puede ocurrir en el caso de organizaciones religiosas que al mismo tiempo crean comunidades), las comunidades se caracterizan por fuertes lazos simbólicos de solidaridad mientras las organizaciones por las jerarquías internas y el control de las relaciones sociales. Las comunidades transestatales son aquellas en las que migrantes y no migrantes estás unidos de manera duradera a través de distintos estados. No es necesario que determinadas personas se muevan continuamente entre dos mundos, pero para que estas comunidades tengan cohesión social y un repertorio común de representaciones colectivas, es necesario que los lazos sociales y simbólicos sean capaces de crear un sentimiento de cercanía. Las organizaciones transestatales cuentan con formas específicas de control burocrático y ejercicio del poder. Es el caso de los partidos políticos, de movimientos sociales constituidos por migrantes laborales o refugiados, de las ya mencionadas organizaciones religiosas o de las corporaciones económicas transnacionales. Sus actividades transestatales están orientadas básicamente a influir en el país de origen.

Entendemos el transnacionalismo migrante no como un fenómeno propio de los tiempos que corren -al contrario, afirmamos que en el pasado también se puede constatar la existencia de espacios transnacionales generados por procesos migratorios- sino como un paradigma nuevo para abordar la migración internacional (sustituyendo los anteriores de push-pull y centroperiferia), un enfoque que viene a unir el nivel micro de las decisiones individuales y el nivel macro de los procesos socioeconómicos:

"El concepto de espacios transestatales sirve al análisis de las transacciones transfronterizas y densificadas y, al mismo tiempo, de las consecuencias que tienen para la autonomía de las personas y de la actuación de los Estados. Permite enfocar tanto los mundos de vida como aspectos sistémicos. Se interesa tanto por las experiencias personales y las prácticas de personas y colectivos, como por la regulación a través de mecanismos sistémicos como dinero, poder y legislación" (Faist, 2000: 17).

Por otro lado, el enfoque transnacional aporta una nueva perspectiva en el abordaje de los procesos de adaptación. Los dos modelos explicativos tradicionales -asimilación y pluralismo étnico- los consideran dentro del contentedor del Estado-nación. Aunque mientras la teoría asimilacionaista prevé una adaptación gradual de los migrantes (grupo minoritario) a la sociedad de acogida (grupo mayoritario), los defensores del pluralismo étnico reclaman el reconocimiento de la cultura de todos los grupos nacionales, étnicos o religiosos que viven dentro del Estado, para que puedan participar en condiciones de libertad e igualdad en la vida pública. La teoría de espacios sociales transnacionales en tanto que modelo de integración alternativo (Faist, 2000a; $2000 \mathrm{~b}$ ), se hace eco del desarrollo de identidades y actividades políticas cruzando las fronteras de los Estados. Estaríamos ante el despliegue de estrate- 
gias transnacionales desde abajo, desarrolladas por actores populares como reacción al proceso de transnacionalización desde arriba (Glick, Basch y Blanc-Szanton, 1992: 11-12; Portes, Guarnizo y Landolt, 1999: 220).

\section{MEMORIAS PERSONALES, MEMORIAS COLECTIVAS}

La perspectiva transnacional permite considerar las migraciones como procesos que tienen lugar al interior de un sistema migratorio y en el que intervienen distintos grupos de actores sociales: además de los propios migrantes, los gobiernos del país de origen y del de destino y las sociedades civiles de ambos países (Faist, 2000: 34). Acorde con el objetivo de abrir un diálogo entre las percepciones de distintos grupos involucrados en el proceso migratorio, nuestra investigación se basó en distintos tipos de fuentes: entrevistas orales, prensa escrita y películas de ficción, además de la producción académica. Se trata de textos producidos por y orientados hacia actores sociales diversos, entendiendo los discursos como acción e interacción social (Van Dijk, 1996: 82-83) ${ }^{6}$. En el plano metodológico, este entrecruzamiento de fuentes se traduce en la complementariedad entre diferentes procedimientos de trabajo, que exponemos a continuación.

Cuando se trata de analizar procesos sociales recientes, el problema del historiador, lejos de residir en la falta de fuentes, se encuentra en la dificultad de realizar una selección dentro del amplio conjunto de materiales que tiene a disposición. La elección depende del objeto y enfoque planteados, de modo que la historia oral se presenta como herramienta ideal cuando el interés está orientado a rescatar las percepciones de los sujetos que protagonizan la migración; la observación participante es adecuada para una contextualización de los testimonios recogidos, puesto que las prácticas les confieren sentido. Por otro lado, el análisis periodístico y cinematográfico nos permite acceder al mundo de las representaciones sociales desde dos ángulos diferentes. La combinación de observación directa y observación documental $^{7}$ permite una interesante conjunción de puntos de vista.

Dicho de otra manera, se trata de poner en diálogo los dos tipos de memoria que distingue Halbwachs (1950: 35-37): por un lado la memoria interior, interna, personal, autobiográfica, individual; por otro, la memoria exterior, social, histórica, colectiva. La memoria individual y la memoria colectiva están en continua interacción, influyéndose mutuamente. La existencia de diversas memorias históricas ${ }^{8}$ es el reflejo de la coexistencia de diferentes culturas políticas en una sociedad o de diversas identidades colectivas, grupales, étnicas, nacionales... En un momento determinado del presente, los mecanismos conscientes e inconscientes de la memoria histórica colectiva actúan de tal modo que recuperan del pasado unas ideas, aconteci- 
mientos, personajes, luchas e interpretaciones mientras otros son suprimidos o echados al olvido. Las identidades individuales y colectivas dependen del recuerdo: éste confiere la sensación de seguir siendo la misma persona, a lo largo de trayectorias fluctuantes, así como el sentimiento de pertenencia a un grupo. Obviamente, qué elementos de la historia son objeto del recuerdo, tiene que ver con las realidades cambiantes del presente? . Por eso la toma de conciencia sobre la interacción entre pasado y presente implica también el reconocimiento de que el marco cronológico es una construcción histórica definida por la propia perspectiva de la investigación ${ }^{10}$. En este sentido, la búsqueda de un equilibrio entre estructura y representación (Bourdieu, 1988: 129) se traduce en la dialéctica entre la fugacidad de la coyuntura -las migraciones argentinas hacia España en los albores del siglo XXI- y el tiempo largo sobre el que se construyen los imaginarios sociales.

\section{EL MUNDO DE LAS EXPERIENCIAS: HISTORIA ORAL Y OB- SERVACIÓN}

Entendemos la historia oral como técnica de observación directa y cualitativa, que utiliza un determinado tipo de fuentes -los testimonios orales-, obtenidas mediante un método de trabajo específico -la encuesta oral(Aceves, 1994: 149; Ortí, 2000: 271), sin que esto implique un uso exclusivo de las mismas. Al contrario, nuestro propósito es el abordaje de las migraciones desde la complementariedad y confrontación de recursos.

La práctica contemporaneidad entre los acontecimientos y su análisis historiográfico permiten al historiador del presente contar con el testimonio de los testigos e interrogarles acerca de su percepción de los hechos históri$\cos ^{11}$, al mismo tiempo que el investigador, al participar activamente en la construcción de las fuentes, también es sujeto de esa historia (Thompson, 1988: 268; Borderías, 1995: 128-129) ${ }^{12}$. Es importante señalar que los acontecimientos y las interpretaciones del pasado son reconstruidos bajo los criterios de significación que tienen en el presente, en el momento de la entrevista (Kholi, 1993: 179-180). De ahí la relevancia de tener en cuenta el tiempo transcurrido entre la historia ocurrida y la historia contada. Por ejemplo, en los relatos sobre las experiencias migratorias es relevante considerar el momento del proceso de asimilación en que se encuentra el entrevistado -si hace mucho que inició el proyecto migratorio o si recién llegó-, pues es un elemento que condiciona su autopercepción de la situación en la que se encuentra, su visión de la sociedad de acogida y su interpretación de la sociedad de origen.

Entre la bibliografía reciente sobre migraciones internacionales a España encontramos distintos estudios que utilizan el método 
de las historias de vida, como es el caso de Ramírez (1996) o Criado (2001). Por su parte el Colectivo Ioé (2004) incluye entre las 20 historias de vida que configuran una investigación que explora los problemas que afectan en la primera etapa de inserción a migrantes procedentes de países periféricos en la Comunidad Valenciana, la historia de una migrante argentina.

Indudablemente, el acceso a la realidad social e histórica por medio de la historia oral privilegia una mirada subjetiva ${ }^{13}$, y así lo destacan los diferentes autores (Bertaux, 1993a: 16714; Fraser; 1993: 86; Marinas y Santamarina, 1993: 10-11; Aceves, 1994: 144; Schwarzstein, 1995: 48; Alonso, 1998: 68-71; Joutard, 1999: 228; Checa, Checa y Arjona, 2002: 371-372). A través de las entrevistas buscamos llegar a la visión que tienen los entrevistados del mundo que les rodea y al sentido de sí mismos en la historia narrada, es decir, a la interpretación que hacen de su mundo. Es inevitable que en su versión de la historia influyan las experiencias vividas: en los discursos de los migrantes argentinos tienen reflejo sus trayectorias. Si a esto unimos que las experiencias de migración suponen para quienes se enfrentan a ellas desafíos significativos al sentimiento de pertenencia, al sentimiento de seguir siendo la misma persona (Grinberg y Grinberg, 1984: 39-40; Chambers, 1994: 19), se entiende que la pregunta por la identidad constituya un elemento importante del proceso migratorio.

En nuestra investigación contamos con algo menos de medio centenar de entrevistas abiertas semidirectivas (Ortí, 2000: 271) ${ }^{15}$ realizadas en 20022003 a migrantes argentinos que en ese momento se encontraban radicados en Madrid, arribados principalmente desde 1999, aunque algunos de ellos ya lo hicieron antes. El cuestionario que sirvió como guía está estructurado en tres partes. La primera contiene preguntas referentes a la sociedad emisora: datos demográficos básicos, perfil socio-económico (origen y situación familiar, cualificación, ocupación profesional) e identidad política. La segunda está enfocada hacia la concreción del proyecto migratorio. La tercera se centra en el proceso de integración social y laboral en la sociedad española. En algunos casos hubo posibilidad de realizar una segunda entrevista, lo que ha aportado alguna información adicional acerca del proceso de integración en la sociedad española ${ }^{16}$. Para la localización de los informantes hemos utilizado la estrategia de "bola de nieve" (Bertaux, 1993: 27), partiendo de diferentes puntos de contacto. La cuestión de la amplitud del universo de entrevistados la hemos resuelto mediante el método de la saturación informativa, es decir, hemos acumulado relatos de migrantes hasta que nos dimos cuenta que se empezaban a repetir, que cada nueva historia de vida venía a confirmar lo que la precedente nos había mostrado, sin aportar ningún elemento estructural nuevo (Bertaux, 1993: 248-250; Pujadas, 2002: 55).

Junto a la recogida de material testimonial oral, hemos recurrido al mé- 
todo de la observación participante (Sanmartín, 2000), que resultó especialmente útil para acercarnos a aspectos relacionados con la interactuación social de los argentinos con otros migrantes -compatriotas o no- así como con la población autóctona. Al acudir a establecimientos frecuentados y/o regentados por argentinos, asistir a reuniones organizadas por la Comisión de Acogida de la Casa Argentina de Madrid, participar en sus mateadas, jornadas, charlas, presentaciones de libros... todo esto ha permitido acercarnos desde la práctica antropológica a la dimensión colectiva del ser migrante argentino en Madrid. Pero no menos importante para la contextualización densa de las experiencias relatadas ha sido el acercamiento a otros aspectos de la vida cotidiana, como la realización de trámites para la regularización de la situación administrativa o las estrategias desplegadas en la búsqueda de trabajo, que hemos podido seguir de cerca. Finalmente, la observación participante ha ejercido como mecanismo de control de la información obtenida en las entrevistas, función que también hemos buscado en el cruzamiento, cuando fue posible, del relato biográfico con el testimonio de otras personas pertenecientes al ámbito social del entrevistado.

\section{EL MUNDO DE LAS REPRESENTACIONES: PRENSA DIARIA Y CINE DE FICCIÓN}

Las representaciones sociales son sistemas de valores, ideas y prácticas que al tiempo que permiten a las personas orientarse en su mundo, facilitan la construcción de identidades grupales (Alonso, 1998: 25-26; Chartier, 1996: $56-57)^{17}$. Si indagamos en la producción periodística y cinematográfica para descifrar los imaginarios sociales ${ }^{18}$ construidos en torno a la migración de argentinos hacia España, es porque nos interesa, precisamente, profundizar en la incidencia que tienen sobre el desarrollo de los propios proyectos migratorios y sobre las relaciones entre españoles y argentinos.

Los medios de comunicación de masas son quizás los agentes más inmediatos en la creación y recreación de una memoria colectiva de la migración argentina. Tienen en su poder no sólo fijar la importancia de los acontecimientos ${ }^{19}$ sino también de hacer escuchar la voz de los actores de la historia (Nora, 1978: 225). Pero los medios de comunicación de masas no sólo efectúan un papel decisivo en la construcción de creencias compartidas ${ }^{20}$ y en la transmisión de valores culturales (Nash, 2005: 17), sino que también inciden sobre las actitudes ${ }^{21}$ que adopta(n) la(s) sociedad(es) frente a una determinada cuestión, en nuestro caso la migración Argentina-España.

Para analizar las representaciones mediáticas que circulan, tanto en origen como en destino, recurrimos a la prensa escrita de gran difusión: Clarín, La Nación y Página/12 en Argentina 22 y ABC, ElMundo y El País en España. 
Temporalmente abarcamos desde mediados de 1999, fecha en la que las secciones deportivas de los periódicos argentinos comienzan a denunciar el drenaje de futbolistas, hasta mediados de 2005, cuando concluye el proceso extraordinario de regularización de inmigrantes llevado a cabo por el gobierno español, hecho relatado extensamente en la prensa. Si durante todo este periodo los medios argentinos se refieren profusamente a la salida de compatriotas, nosotros centramos nuestra atención en aquellas noticias acerca de la migración de argentinos a España -que, por otra parte, es el destino más tenido en cuenta-. En el caso de la prensa española, Argentina es quizás la nación latinoamericana que mejor cobertura recibe. La crisis que estalla en navidades de 2001 tiene un extraordinario impacto en los medios españoles y durante varias semanas el país austral copa los titulares de la sección internacional de los periódicos. Más allá de esta coyuntura, lo argentino tiene una presencia continuada en los medios españoles, especialmente en las secciones de cultura -literatura, música, cine- y deportes. Nosotros, sin embargo, fijamos el interés en las informaciones que nos permiten rastrear la presencia de argentinos en España. Para ello no vale revisar los apartados dedicados a inmigración en busca de noticias relativas al colectivo argentino: si en la época estudiada la llegada y presencia de personas procedentes de países del Sur ocupa un lugar importante en la agenda mediática y pública, la población argentina es ante todo invisible como "inmigrante". En su lugar la encontramos ampliamente dispersa en las noticias y reportajes más diversos, como ciudadanos de origen argentino que se destacan en el mundo cultural y deportivo, o que se desempeñan profesionalmente; alternativamente, como españoles retornados. Por otro lado, son no pocos los periodistas, escritores o analistas argentinos que colaboran habitualmente en los periódicos analizados.

Indudablemente el proceso de transnacionalización abierto en los años ochenta por vía de las inversiones directas de capitales españoles o mediante la distribución afecta también a sectores como la prensa escrita, a pesar de que ésta presenta una serie de características que, al identificarla con una cultura nacional, dificultan su internacionalización (Bustamante, 1989: 420-422). Por ello, al comparar los discursos mediáticos producidos en los contextos español y argentino pretendemos también determinar hasta qué punto las representaciones circulan atravesando las fronteras nacionales.

Frente a la mirada fugaz y los diagnósticos rápidos de la prensa, recurrimos a las fuentes cinematográficas ${ }^{23}$ para analizar, paralela y complementariamente, las representaciones de la migración Argentina - España reciente en el séptimo arte. En los orígenes de la historia social del cine se encuentra la idea de que las películas producidas en un país reflejan su mentalidad colectiva ${ }^{24} \mathrm{y}$ en este sentido se puede afirmar que todas las películas de ficción son históricas (Caparrós, 1997: 11-12). Caparrós (1998: 32-42) propone una 
clasificación en función de la relación que sus autores establecen con el pasado que retratan. En primer lugar, tendríamos los filmes de reconstrucción histórica o de valor histórico-sociológico: sin voluntad directa de hacer historia, poseen un contenido social y con el tiempo pueden convertirse en testimonios históricos importantes de la gente de una época, su modo de vivir, sentir, comportarse, vestir, hablar. Segundo, los filmes de ficción histórica serían aquellos que evocan un episodio de la historia o se basan en determinados personajes históricos, con el fin de narrar acontecimientos del pasado, aunque su enfoque histórico no sea riguroso. Finalmente, los filmes de reconstitución histórica podrían ser definidos como "aquellos que, con una voluntad directa de 'hacer Historia', evocan un período o hecho histórico, reconstituyéndolo con más o menor rigor, dentro de una visión subjetiva de cada realizador. Se trata, pues, de un trabajo artístico-creativo que está más próximo a la operación historiográfica moderna que al libro de divulgación”’25. Aunque esta categorización de las películas de ficción o argumentales nos parece útil en tanto que atiende a las intencionalidades de los cineastas que las producen, resulta difícil encasillar las obras que proponemos en una de las categorías, pues, como el mismo Caparrós reconoce, en la práctica, los tres niveles se solapan frecuentemente. Recuérdese, además, que nuestro objeto pertenece al presente y, por consiguiente, el tiempo histórico relatado es simultáneo al momento de producción y proyección de los filmes.

Hemos elegido dos películas -Lugares comunes, dirigida por Aristarain (2002) y Bar "El Chino", de Burak (2003)- para realizar un análisis exhaustivo, que es complementado por el recurso a un conjunto más amplio de films de los que abordamos aspectos más puntuales, sin ofrecer una visión del conjunto: Martín (Hache) (Aristarain, 1997), Nueces para el amor (Lecchi, 2000), Luna de Avellaneda (Campanella, 2004), El método (Piñeyro, 2005), Abrígate (Costafreda, 2007) y otras. Imprescindible es también la referencia a Vientos de agua de Campanella (2005), proyectada como serie de televisión en 13 capítulos y, más tarde, editada en DVD. Para la selección hemos considerado, además de la afinidad temática con el objeto de la migración argentina reciente y su realización prácticamente paralela a los acontecimientos narrados, su nivel de difusión: privilegiamos aquellos films de ficción que tuvieron una más amplia repercusión en el público, tanto argentino como español. La mayoría de las películas tienen en común que son coproducciones, es decir, producto de una actividad económica y cultural transnacionalizada, y que fueron estrenadas tanto en Argentina como en España. Si bien se encuentran lejos de tener un público tan masivo como la industria hollywoodiense, ocupando parcelas bastante limitadas dentro del consumo cultural de la sociedad argentina y española, responden a los intereses y gustos de determinados sectores tanto allá como aquí.

Volviendo a la consideración del cine como fuente histórica relevante 
para el análisis de las sociedades contemporáneas, lo vinculamos ante todo al ámbito de las representaciones de la realidad ${ }^{26}$. Podemos entender la realización de un film como proceso de producción de sentido que tiene su contraparte en la lectura que de él hacen los espectadores (Cuesta, 2004: 21-2227). En lo que a la interpretación de los procesos históricos se refiere, Montero (2001: 32) nos hace ver que la explicación que ofrece el cine es la única a la que tiene acceso el gran público ${ }^{28}$. Esta importancia sobrepasa las salas de proyección, incrementándose con el consumo de cine a través de la pequeña pantalla, pues se inserta en la normalidad cotidiana (Montero, 2001: 32). En cuanto a los resultados de la incorporación de las fuentes cinematográficas al análisis histórico, Ferro (1995: 22-23) resalta su papel en la incorporación de agentes de la historia que de otro modo permanecen ocultos ${ }^{29}$. La comparación de diferentes discursos sobre la historia permitiría descubrir, a través de esta confrontación, una realidad no visible (Ferro, 1995: 65). En esta línea, uno de los diálogos que buscamos establecer es entre las explicaciones historiográficas y las del cine ${ }^{30}$.

Finalmente, unas palabras sobre el acercamiento que pretendemos y que, lógicamente, no tiene que ver con un análisis estético de los filmes de ficción, sino con la interpretación socio-histórica ${ }^{31}$. Para fundamentarlo, rescatamos la propuesta de sistematización metodológica de Caparrós y Alegre (1996), que establecen cuatro fases de análisis. Primero, la contextualización de las películas, tanto en los procesos históricos que retratan como en la producción fílmica -en nuestro caso estos dos momentos coinciden en el tiempo-. Segundo, analizamos el proceso de creación artística e industrial: la producción (autores, productores, aspectos económicos, rodaje), la distribución (compañía, nacionalidad de la productora, publicidad) y exhibición (salas, ciudades, circuitos de distribución geográfica). En tercer lugar, el análisis propiamente dicho del film: temática, fuentes, relación con otras películas, tipología de personajes, trama, tratamiento de los elementos estéticos (tipo de enfoque, plano, ángulo de las tomas, luz, espacio, tiempo, voces, iluminación, montaje, sonido). Y cuarto, se indaga la acogida del film en el público: crítica periodística, estadísticas, emisiones de televisión, edición en video o DVD, reacción de los historiadores, remakes, impacto a largo plazo en la sociedad y en la historia del cine. En resumidas cuentas, se trata de abordar el contexto de producción y recepción de las películas ${ }^{32}$.

\section{REFERENCIAS BIBLIOGRÁFICAS}

Aceves Lozano, Jorge Eduardo (1994). "Práctica y estilos de investigación en la historia oral contemporánea". Historia y Fuente Oral, 12, pp. 143-150.

Actis, Walter (2005). "Las políticas migratorias y su impacto en las formas 
de inserción de la población inmigrante en España”. En Casa Argentina de Madrid. Migraciones: claves del intercambio entre Argentina y España. Buenos Aires: Siglo XXI, pp. 135-155.

-; Esteban, Fernando O. (2007). "Argentinos hacia España ("sudacas" en tierras "gallegas”): el estado de la cuestión”. En Novick, Susana (dir.). Sur-Norte. Estudios sobre la reciente emigración de argentinos. Buenos Aires: Catálogos, pp. 205-258.

Alonso Benito, Luis Enrique (1988). La mirada cualitativa en sociología: una aproximación interpretativa. Madrid: Fundamentos.

Aróstegui Sánchez, Julio (1990). "Sociología e historiografía en el análisis del cambio social reciente”. Historia Contemporánea, 4, pp. 145-172.

- (2004). La historia vivida. Sobre la historia del presente. Madrid: Alianza.

- (2004a). “La historia del presente. ¿Una cuestión de método?”. En Navajas Zubeldia, Carlos (ed.). Actas del IV Simposio de Historia Actual, Logroño, 17-19 de octubre de 2002. Logroño: Gobierno de La Rioja - Instituto de Estudios Riojanos, pp. 41-75.

Bertaux, Daniel (1993). "De la perspectiva de la historia de vida a la transformación de la práctica sociológica”. En Marinas, José Miguel; Santamarina, Cristina (eds.). La bistoria oral: Métodos y experiencias. Madrid: Debate, pp. 19-34.

(1993a). "La perspectiva biográfica: validez metodológica y potencialidades". En Marinas, José Miguel; Santamarina, Cristina (eds.). La historia oral: Métodos y experiencias. Madrid: Debate, pp. 149-171.

Borderías, Cristina (1995). "La historia oral en España a mediados de los noventa". Historia y Fuente Oral, 13, pp. 113-129.

Bourdieu, Pierre (1988). Cosas dichas. Buenos Aires: Gedisa.

Braudel, Fernand (1979). La Historia y las Ciencias Sociales. Madrid: Alianza.

Bustamante, Enrique (1989). "La transnacionalización de la comunización y la cultura”. En Timoteo Álvarez, Jesús (et al.). Historia de los medios de comunicación en España: periodismo, imagen y publicidad (1900-1990). Barcelona: Ariel, pp. 419-426.

Caparrós Lera, José María; Alegre, Sergio (1996). “Análisis histórico de los films de ficción”. Cuadernos cinematográficos, 10, pp. 7-26.

(1997). "Relaciones Historia-Cine en el contexto español”. En Yraola, Aitor (comp.). Historia contemporánea de España y cine. Madrid: Universidad Autónoma de Madrid, pp. 11-26.

(1998). La guerra de Vietnam, entre la bistoria y el cine. Barcelona: Ariel.

Chambers, Iain (1994). Migración, cultura, identidad. Buenos Aires: Amorrortu. 
Chartier, Roger (1996). El mundo como representación. Historia cultural: entre práctica y representación. Barcelona: Gedisa.

Checa, Francisco; Checa Olmos, Juan Carlos; Arjona Garrido, Ángeles (2002). "Las historias de vida como técnica de acercamiento a la realidad social. El caso de las migraciones". En Checa, Francisco (ed.). Las migraciones a debate. De las teorías a las prácticas sociales. Barcelona: Icaria, pp. 347-383.

Colectivo Ioé (Walter Actis, Miguel Ángel de Prada, Carlos Pereda) (2004). 'Igual de seres humanos'. Historias de inserción de migrantes con problemas en la Comunidad Valenciana. Valencia: Centro de Estudio para la Integración Social y Formación de Inmigrantes.

Criado Calvo, María Jesús (2001). La línea Quebrada. Historias de vida de migrantes. Madrid: Consejo Económico y Social.

Croce, Benedetto (1960). La historia como hazaña de la libertad. México: Fondo de Cultura Económica.

Cuesta Bustillo, Josefina (1993). Historia del presente. Madrid: Eudema.

_- (1998). “Memoria e historia. Un estado de la cuestión”. Ayer, 32, pp. 203-246.

- (2004). "Del cine como fuente histórica". En Del Amo, Alfonso (et al.). Apuntes sobre las relaciones entre el cine y la historia (El caso español). Salamanca: Junta de Castilla y León Consejería de Cultura y Turismo, pp. 13-24.

De Meyer, Eugenia W. (1995). "Los nuevos caminos de la historia oral en América Latina". Historia y Fuente Oral, 13, pp. 97-102.

De Pablo Contreras, Santiago (2001). "Cine e historia: ¿La gran ilusión o la amenaza fantasma?”. Historia Contemporánea, 22, pp. 9-28.

Duverger, Maurice (1976). Métodos de las ciencias sociales. Barcelona: Ariel, 1976.

Faist, Thomas (2000). "Grenzen überschreiten. Das Konzept Transstaatliche Räume und seine Anwendungen”. En Faist, Thomas (ed.). Transstaatliche Räume. Politik, Wirtschaft und Kultur in und zwischen Deutschland und der Türkei. Bielefeld: transcript, pp. 9-56.

- (2000a). "Jenseits von Nation und Postnation. Eine neue Perspektive für die Integrationsforschung”. En Faist, Thomas (ed.). Transstaatliche Räume. Politik, Wirtschaft und Kultur in und zwischen Deutschland und der Türkei. Bielefeld: transcript, pp. 339-392.

- (2000b). "Transnationalization in international migration: implications for the study of citizenship and culture". Ethnic and Racial Studies, 23, 2, pp. 189-222.

Ferro, Marc (1995). Historia contemporánea y cine. Barcelona: Ariel.

Fraser, Ronald (1993). "La Historia Oral como historia desde abajo". Ayer, 12, pp. 79-92.

Glick Schiller, Nina; Basch, Linda; Blanc-Szanton, Cristina (1992). Towards a transnational perspective on migration. Race, class, ethnicity and nacionalism reconsidered. Nueva York: New York Academy 
of Sciences.

Grinberg, León; Grinberg, Rebeca (1984). Psicoanálisis de la migración y del exilio. Madrid: Alianza.

Halbwachs, Maurice (1950). La mémoire collective. París: Presses Universitaires de France.

Joutard, Philippe (1999). Esas voces que nos llegan del pasado. Buenos Aires: Fondo de Cultura Económica.

Kholi, Martin (1993). "Biografía: relato, texto, método". En Marinas, José Miguel; Santamarina, Cristina (eds.). La historia oral: Métodos y experiencias. Madrid: Debate, pp. 173184.

Kracauer, Siegfried (1961). De Caligari a Hitler: Una historia psicológica del cine alemán. Barcelona: Paidós.

Kritz, Mary M.; Lim, Lin Lean; Zlotnik, Hania (eds.) (1992). Internationalmigration systems. A global approach. Oxford: Clarendon.

Marinas, José Miguel; Santamarina, Cristina (eds.) (1993). La historia oral: Métodos y experiencias. Madrid: Debate.

Montero Díaz, Julio (2001). "Fotogramas de papel y libros de celuloide: el cine y los historiadores: Algunas consideraciones”. Historia Contemporánea, 22, pp. 29-66.

Nash, Mary (2005). Inmigrantes en nuestro espejo: inmigración y discurso periodístico en la prensa española. Barcelona: Icaria.

Navajas Zubeldia, Carlos (2003). "El regreso de la 'verdadera' historia contemporánea”. Revista de Historia Actual, 1, pp. 143-162.

Nora, Pierre (1978). "La vuelta del acontecimiento". En Le Goff, Jacques; Nora, Pierre (dirs.). Hacer la Historia. I: Nuevos problemas. Barcelona: Laia, pp. 221-239.

Ortí, Alfonso (2000). "La apertura y el enfoque cualitativo o estructural: la entrevista abierta semidirectiva y la discusión de grupo”. En García Ferrando, Manuel; Ibáñez, Jesús; Alvira Martín, Francisco (comps.). El análisis de la realidad social. Métodos y técnicas de investigación (3 ${ }^{a}$ edición). Madrid: Alianza, pp. 219-282.

Pérez Serrano, Julio (2003). "La historia continúa". Historia Actual Online, 1. <http://www.historia-actual.com/hao/Volumes/Volume1/Issue1/esp/v1i1c1.pdf> (acceso, 19-01-2010).

Portes, Alejandro; Guarnizo, Luis Eduardo; Landolt, Patricia (1999). "The study of transnationalism: pitfalls and promise of an emergent research field". Ethnic and Racial Studies, 22, 2, pp. 217-237.

Pujadas Muñoz, Juan José (2002). El método biográfico: El uso de las historias de vida en ciencias sociales. Madrid: Centro de Investigaciones Sociológicas. 
Ramírez Goicoechea, Eugenia (1996). Inmigrantes en España: vidas y experiencias. Madrid: Centro de Investigaciones Sociológicas - Siglo XXI.

Sanmartín, Ricardo (2000). ‘La observación participante”. En García Ferrando, Manuel; Ibáñez, Jesús; Alvira Martín, Francisco (comps.). El análisis de la realidad social. Métodos y técnicas de investigación (3ª edición). Madrid: Alianza, pp. 145-165.

Santamaría, Enrique (2002). La incógnita del extraño: una aproximación a la significación sociológica de la "inmigración no comunitaria". Barcelona: Anthropos.

Schwarzstein, Dora (1995). "La historia oral en América Latina". Historia y Fuente Oral, 14, pp. 39-50.

Sorlin, Pierre (1977). Sociologie du cinéma: ouverture pour l'histoire de demain. Paris: Aubier Montaigne.

Thompson, Paul (1988). La voz del pasado: L a bistoria oral. Valencia: Alfons el Magnànim.

_- (1993). "Historias de vida en el análisis de cambio social”. En Marinas, José Miguel; Santamarina, Cristina (eds.). La historia oral: Métodos y experiencias. Madrid: Debate, pp. 65-80.

Van Dijk, Teun A. (1996). La ciencia del texto: un enfoque interdisciplinario. Barcelona: Paidós.

Van Dijk, Teun A. (1997). Racismo y análisis crítico de los medios. Barcelona: Paidós.

Wechsler, Diana B.; Aznar, Yayo (comps.) (2005). La memoria compartida. España y la Argentina en la construcción de un imaginario cultural (1898-1950). Buenos Aires: Paidós, pp. 15-27.

\section{NOTAS}

${ }^{1}$ Los empadronados ascienden a 93.700 (inicios de 2001), 131.900 (2002), 209.900 (2003), 225.200 (2004) y 257.200 (2005). La condición jurídica de estos migrantes es diversa: por un lado, los poseedores de una nacionalidad comunitaria (principalmente españoles, pero también italianos); por otro, los de nacionalidad argentina, entre los que hay que distinguir los que tienen permiso de residencia y los que se encuentran en situación de irregularidad. A partir de aquí una parte de los huidos del corralito (se desconoce en qué cantidad), retorna a la Argentina desalentado por las frustración de sus expectativas iniciales y/o impulsado por la relativa estabilización económica en origen (Actis y Esteban, 2007: 228-232).

${ }^{2}$ También denominada Historia Actual o Historia Reciente o Historia Inmediata... Histoire du temps présent, en su denominación original en francés, Zeitgeschicbte en alemán, contemporary bistory en inglés. Acerca de este modelo historiográfico véase: Aróstegui (2004), Cuesta (1993), Navajas (2003), Pérez Serrano (2003).

3 "At the bases of the systems approach to the study of international migration is the concept of a migration system constituted by a group of countries that exchange relatively large numbers of migrants with each other. At a minimum, a migration system includes at least two countries, although, ideally, one would include in a system all countries linked by large 
migration flows. (...) Such flows occur within national contexts whose policy, economic technological, and social dimensions are constantly changing, partly in response to the feedbacks and adjustments that stem from the migration flow itself. People move in both directions, from county A to B and vice versa, possibly in multiple stages as the number of countries included in the system increase beyond the minimum of two. Moreover, population exchanges within the system involve not only permanent migrants, migrant workers, or refugees, but also students, military personnel, business men, and even tourists since such short-term movements frequently set the conditions for subsequent long-term ones" (Kritz y Zlotnik, 1992: 2-3).

${ }^{4}$ La traducción es nuestra. Faist utiliza el calificativo "transestatal" (transstaatlich) frente al habitual "transnacional" (transnational), por tres razones: para hacer notar que en el tratamiento de las migraciones que cruzan las fronteras lo relevante son las cuestiones relacionadas con la acción del Estado, la ciudadanía o la sociedad civil (no las relaciones entre nacionalidades que, además, en muchos casos no son una única dentro del propio Estado); porque el análisis se centra, precisamente, en personas, redes y organizaciones no gubernamentales que actúan más allá de las fronteras, por debajo y paralelamente al nivel gubernamental; y porque en muchos casos las causas de la migración interestatal son conflictos originados por proyectos de estados-nación fallidos (Faist, 2000a: 13-14). En este texto utilizamos "transestatal" y "transnancional" indistintamente.

${ }^{5}$ Acerca de la distinción entre lazos sociales y simbólicos: "Los lazos sociales representan una serie continuada de transacciones interpersonales -es decir, comunicaciones aisladas entre al menos tres actores-, a las que los implicados adscriben intereses, compromisos, expectativas y normas comunes. Los lazos simbólicos son transacciones continuadas que se pueden producir de manera directa o indirecta y a las que los implicados ligan significados, recuerdos, expectativas de futuro y símbolos. Los lazos simbólicos pueden alcanzar más allá de las relaciones personales, en tanto que se orientan de manera más general a miembros de una misma creencia, lengua, etnicidad o nacionalidad. El capital social refiere a los recursos inherentes a los lazos sociales, que permiten a una persona cooperar con otras a través de redes, grupos u organizaciones. El capital social representa una serie de mecanismos que contribuyen al fortalecimiento o, en caso de su ausencia, al debilitamiento de la cooperación. El capital cultural se refiere a recursos contenidos y movilizables en los lazos simbólicos. Une a través de sentimientos de pertenencia colectiva de personas, redes, comunidades y organizaciones. De esta manera, el capital social y cultural son recursos a la vez individuales y colectivos. Posibilitan a las personas perseguir sus intereses a través de redes y colectivos y a los colectivos integrar a las personas en un grupo y someterlas a su control" (Faist, 2000a: 28-29).

${ }^{6}$ La acción comunicativa tiene por objeto modificar el conocimiento y comportamiento del interlocutor. Los discursos, representaciones de la realidad realizadas por determinados actores y grupos sociales (Alonso, 1998: 204), nos interesan en tanto productores y reproductores de relaciones sociales en el espacio. Por eso, mientras el análisis de contenido se centra en las significaciones de los textos, el análisis crítico del discurso desarrollado por Van Dijk (1996) se pregunta también por las relaciones entre el contexto de producción y recepción que los explica y determina. 
${ }^{7}$ Véase el criterio de Duverger (1976) de clasificación de las técnicas de investigación histórica, según la manera de obtención de los datos: mientras las técnicas de observación documental son las aplicables al estudio de los "documentos" (éstos, en variados tipos de soportes: escritos, visuales o sonoros) que nos dan una observación mediata de la realidad, las técnicas de observación directa son las que construyen ellas mismas los documentos: muestreo, entrevista, encuesta, tests, observación participante, intervención sociológica. Estas técnicas de observación directa, a su vez, se pueden clasificar en función del grado de intervención del investigador en la preparación de la documentación: extensivo (muestreo, cuestionario repartido, encuestas) o intensivo (tests, entrevistas, intervención y observación participante). Esta sistematización permite poner de relieve el papel activo del investigador que utiliza técnicas de observación directa. Acorde con esta clasificación, Aróstegui (2004a: 75) distingue, técnicamente, entre fuentes orales estandariz̧adas -como los relatos de vida- y las fuentes orales construidas, que el historiador prepara en función de lo que pretende investigar. La diferenciación de Pujadas (2002: 11-12) responde a los mismos criterios: documentos personales ("cualquier tipo de registro no motivado o incentivado por el investigador durante el desarrollo de su trabajo, que posea un valor afectivo y/o simbólico para el sujeto analizado") y registros biográficos obtenidos por encuesta. Finalmente, no está de más recordar que historia oral no es sinónimo de documentos testimoniales. El método biográfico desarrollado por Bertaux (1993a) consolida la distinción entre: life stories o relatos de vida (la historia de una persona relatada por ella misma) y life histories o bistorias de vida (el estudio de caso sobre una persona, comprendiendo no sólo su life story, sino cualquier otro tipo de información o documentación adicional que permita la reconstrucción de su biografía).

${ }^{8}$ Recorriendo la historia de la memoria, las memorias son plurales y diversas (Cuesta, 1998: 210-215).

${ }^{9}$ Así, Wechsler y Aznar (2005: 20) muestran que la memoria compartida entre España y Argentina no implica que ambos países, a pesar de compartir un pasado, tengan que rescatar necesariamente los mismos hechos, sino que eso responde a las estrategias políticas que forman esta memoria.

${ }^{10}$ Croce (1960: 271 y ss.) señala que la historia es siempre contemporánea, dado que la reflexión siempre se realiza desde nuestro presente. Esto quiere decir que la temporización, la ordenación del pasado, se define "desde un nosotros, desde un nuestro tiempo" (Aróstegui, 2004: 57). En consecuencia, los límites cronológicos son móviles: aunque conocemos el punto de llegada -una realidad actual inconclusa-, el punto de partida de los fenómenos estudiados todavía ha de ser determinado (Aróstegui, 1990: 169).

${ }^{11}$ Puede ser entendida, también, como una específica historia oral, "como una sectorialización historiográfica, como una especialidad temática, e incluso, como una especialización cronológica, con lo que nos salimos del ámbito de las técnicas e incluso de la teoría disciplinar de la historiografía para enfrentarnos con una parte sustantiva del estudio de la historia" (Aróstegui, 1995: 413).

${ }^{12}$ El historiador británico Paul Thompson, militante de la people’s history, viene a identificar la historia oral como "historia desde abajo", interesada en ámbitos de la realidad social desatendidos por la historiografía convencional: los grupos marginados, discriminados, some- 
tidos, analfabetos. Al dar voz a los "sin voz" propone una historia que forme parte del saber colectivo y que parta de los intereses de la gente corriente. Es así que la historia oral selecciona nuevos sujetos sociales (Thompson, 1988: 289-290; Aceves, 1994: 143-144), haciendo visibles a los migrantes como actores de la historia. Al mismo tiempo, la historia oral resulta útil para nuevos ámbitos historiográficos o focos de interés: en lo que a nuestro caso se refiere, nos permite indagar en las redes de sociabilidad de los migrantes o en la organización familiar, en cuestiones de la vida cotidiana, en el mundo de las representaciones o de lo simbólico, en los procesos de construcción de identidades individuales y grupales, en la inserción laboral, etc. Más acerca de los ámbitos privilegiados de la historia oral en: De Meyer (1995: 98 y ss.), Borderías (1995: 121 y ss) y Schwarzstein (1995: 42).

${ }^{13} \mathrm{Si}$ la historia oral se va construyendo a partir del diálogo entre el historiador y el informante (Thompson, 1988: 276), se produce un intercambio entre historia y sociedad que exige una actitud abierta en la formulación de hipótesis: éstas se pueden ver modificadas por los propios agentes sociales (Thompson, 1993: 65-80) o incluso deberían ser formuladas al final como resultado de la observación de las relaciones sociales (Bertaux, 1993: 25). Pero quizás escuchar con atención a las fuentes no debería ser una práctica exclusiva de la historia oral.

${ }^{14}$ La historia de las mentalidades remarca que no sólo importan los hechos históricos, sino también cómo esa realidad social es percibida por los sujetos que la viven: la estructura mental o la cosmovisión compartida por un determinado momento (Ariès, 1988: 481). Se trata de un "inconsciente colectivo", que se impone a los contemporáneos sin que éstos se den cuenta, influye también sobre las conductas y los comportamientos sociales.

${ }^{15}$ Para el sociólogo francés el nivel socioestructural "objetivo" y el socio-simbólico "subjetivo" son las dos caras de una misma realidad social e histórica (Bertaux, 1993a: 154-158).

${ }^{16}$ A medio camino entre lo que Thompson (1988: 224 y ss.) denomina "cuestionario cerrado" y la "entrevista libre". Con ello nos aseguramos la obtención de información sobre los puntos que nos interesan, al tiempo que ofrecemos un margen de flexibilidad para que los entrevistados expresen libremente su manera de ver la realidad.

${ }^{17}$ Thompson (1988: 266 y ss.) distingue tres formas de presentar la historia oral, dependiendo del objetivo de la investigación: la narración de la historia de una sola vida, el conjunto de historias -bien un conjunto de relatos completos o un montaje de extractos por temas- y el análisis global, en el que la evidencia oral está al servicio de la lógica interna de la argumentación, a la que aporta materiales. Obviamente, en nuestro caso estaríamos ante el último supuesto.

${ }^{18}$ Es interesante la definición del filósofo británico Taylor (2006: 37-38): "Por imaginario social entiendo algo mucho más amplio y profundo que las construcciones intelectuales que puedan elaborar las personas cuando reflexionan sobre la realidad social de un modo diferenciado. Pienso más bien en el modo en que imaginan su existencia social, el tipo de relaciones que mantienen unas con otras, el tipo de cosas que ocurren entre ellas, las expectativas que se cumplen habitualmente y las imágenes e ideas normativas más profundas que subyacen a esas expectativas. Existen importantes diferencias entre un imaginario social y una teoría social. Adopto el término imaginario 1) porque me refiero concretamente a la forma en que las personas corrientes 'imaginan' su entorno social, algo que la mayoría de las veces 
no se expresa en términos teóricos, sino que se manifiesta a través de imágenes, historias y leyendas. Por otro lado, 2) a menudo la teoría es el coto privado de una pequeña minoría, mientras que lo interesante del imaginario social es que lo comparten amplios grupos de personas, si no la sociedad en su conjunto. Todo lo cual no lleva a una tercera diferencia: 3 ) el imaginario social es la concepción colectiva que hace posibles las prácticas comunes y un sentimiento ampliamente compartido de legitimidad. A menudo sucede que lo que comienza como una teoría mantenida por un grupo de personas comienza a infiltrarse en el imaginario social, tal vez primero el de las élites, y luego el del conjunto de la sociedad."

19 "La forma en que se piensan y tratan, en que se problematizan, las actuales migraciones posnacionales es, en gran medida, cosa de metáforas. Si nos detenemos a mirar las prácticas y las retóricas acerca de aquéllas veremos que, con el fin de ubicar social y simbólicamente la llegada de migrantes a la sociedad española, se ha recurrido a una densa metaforización que hace de la inmigración un fenómeno inquietante y preocupante" (Santamaría, 2002: 118).

${ }^{20} \mathrm{Al}$ calificarlo de mediático, Nora (1978: 221-239) redefine el concepto de acontecimiento como objeto de interés histórico, no vinculado al pasado, como en la historiografía positivista, sino al presente y vinculado a los medios de comunicación de masas. En este sentido, indica: "El acontecimiento se le ofrece (al historiador), a partir de ahora, desde el exterior, con todo el peso de un dato, antes de su elaboración, antes del trabajo del tiempo. E incluso con tanta mayor fuerza que los mass media imponen inmediatamente lo vivido como historia y que el presente nos van imponiendo, cada día más, lo vivido" (Nora, 1978: 227). Aunque en la creación del acontecimiento el historiador se encuentra en desventaja respecto a los medios de comunicación, sí está capacitado para encontrar la significación de esos acontecimientos.

${ }^{21}$ Los medios son inseparables de la formación de opinión pública, son fundamentales en el establecimiento de los temas prioritarios en la agenda y en la creación de la realidad: "La mayor parte de nuestro conocimiento social y político, así como nuestras creencias sobre el mundo, emanan de las decenas de informaciones que leemos o escuchamos a diario. Es muy probable que no exista ninguna otra práctica discursiva, aparte de la conversación cotidiana, que se practique con tanta frecuencia y con tanta gente como son el seguimiento de noticias en prensa y televisión" (Van Dijk, 1997: 29-30).

${ }^{22}$ Atendiendo a la sociedad de acogida, se ha dicho que las opiniones y actitudes hacia los inmigrantes dependen en gran medida de las informaciones de los medios de comunicación y de cómo se encuadra esa información: "Los encuadres noticiosos (news frames) hacen referencia a un interrogante básico vinculado con la producción de las noticias: qué incluir y qué enfatizar en un relato informativo. El proceso está relacionado con dos operaciones básicas: seleccionar (incluir-excluir) y enfatizar (hacer saliente), palabras, expresiones e imágenes, para conferir un punto de vista, una perspectiva o un ángulo determinado a una información" (Igartua et al., 2007: 199).

${ }^{23}$ La Nación, de orientación ideológica conservadora, se viene publicando en Buenos Aires desde la segunda mitad del siglo XIX y Clarín, de tendencia progresista, desde mediados del siglo XX; frente a estos diarios clásicos del periodismo argentino, Página/ 12 nació en 1987, 
en la coyuntura de la transición democrática. De tirada menor que los dos primeros, contribuye, sin embargo, a enriquecer el imaginario construido en torno a la salida de argentinos al exterior.

${ }^{24}$ Quienes vienen reflexionando sobre la interrelación entre ciencia histórica y cine, señalan que éste, en tanto testimonio de la sociedad que lo produce y lo recibe, es una fuente relevante para los científicos interesados en el análisis de las sociedades del pasado y del presente, al tiempo que reconocen el valor didáctico de este medio en la enseñanza de la historia (Ferro, 1995: 31-32; Caparrós, 1997: 11; De Pablo, 2001: 15-16). Finalmente, Rosenstone (1997: 13-23) considera el cine como un medio de expresión para la elaboración de un discurso histórico, como nueva forma de escribir la historia -"un nuevo tipo de historia"-. Para hacer del recurso audiovisual, con sus reglas dramáticas y de ficción, una vía para reconstruir e interpretar el pasado, el historiador debe estudiar las posibilidades que un realizador tiene de plasmar el pasado en imágenes (véase también De Pablo, 2001: 23-24).

${ }^{25}$ El pionero es Kracauer (1961), quien realizó un estudio sobre el cine producido durante la república de Weimar para descubrir la psicología colectiva del pueblo alemán. Al ser una obra colectiva mucho más que individual y estar orientadas a las masas, las películas reflejarían mucho más que otras manifestaciones artísticas la mentalidad de una sociedad. No obstante, a estas alturas del desarrollo histórico y de la investigación social, tal vez habría que señalar que la producción cinematográfica no necesariamente representa a la sociedad en su conjunto, y que puede haber corrientes con las que sólo se identifican determinados sectores sociales. Por su parte, el sociólogo Sorlin (1977) indica que los filmes nos hablan mucho más de la sociedad que los produce y al que se dirigen que del pasado al que se refieren.

${ }^{26}$ Éstos últimos serían fundamentales como fuentes de investigación histórica y como medio didáctico. Pero precisarían de un análisis riguroso para ver qué aportan a la ciencia histórica. Por tanto, las películas de reconstitución histórica, a veces, nos dicen más de cómo pensaban o piensan los hombres y las mujeres de una generación y la sociedad de una determinada época sobre un hecho histórico pretérito que acerca del mismo hecho en sí; es decir, clarifica más el hoy o el ayer -el contexto en que ha sido realizado el film- que la Historia evocada (Caparrós: 1998: 39-40). Haciendo referencia a su capacidad de interpelación de la historia, Rosenstone (1997) distingue entre filmes históricos típicos y posmodernos: éstos últimos serían aquellos que suscitan preguntas sobre las certidumbres establecidas, que revisan y reinventan la historia.

27 "Interesa el cine o la película y su historicidad, no tanto por el tema, sino por la sociedad que se le adhiere y puede ser analizada, no sólo como fuente, sino también como producto, como imagen y objeto, y por el análisis de las condiciones de producción, de circulación y de consumo de la película" (Cuesta, 2004: 20).

28 “Como punto de partida es preciso fijar una dualidad necesaria: la previa identificación, como diferentes, distantes y distintos, del objeto (el film) y el sujeto (el espectador) y de sus respectivos mundos de origen. Pues no hay 'encuentro' o relación fructífera entre el objeto y el sujeto -el visionado de una película por un espectador- más que a condición de una distancia antecedente y de una dualidad entre ambos, primero experimentada, luego superada" (Cuesta, 2004: 18). 
${ }^{29}$ Los historiadores no tienen el monopolio de la memoria colectiva de las sociedades, de meditar sobre la historia, ni pueden pretender tenerlo (Rosenstone, 1997; Montero, 2001: 39), cualquier film es una forma de contar la historia (Cuesta, 2004: 23). Si buena parte de la visión que las sociedades actuales tienen del pasado corresponde más a lo que el cine ha divulgado que a lo aprendido en libros o documentales de historia, Montero hace el ejercicio de contraponer los resultados de la investigación histórica que se dan a conocer normalmente mediante publicaciones, y la producción cinematográfica: "En términos sencillos, podría decirse que la diferencia radical entre los lectores de libros de historia y las audiencias de películas históricas es que los primeros son bien conocidos y están bien determinados. Los libros de historia están dirigidos -normalmente- a gentes con cierta formación, cuando no son profesionales o especialistas e la materia. Otra posibilidad es el libro de texto dirigido a estudiantes de secundaria o universitarios: también en este caso el público está bastante bien determinado de antemano. Las películas, también las históricas, tienen otras exigencias respecto a las audiencias: han de llegar a un público necesariamente amplio por imperativos financieros. Esto supone que quienes acuden a las salas carecen formalmente de formación histórica. Acuden a ver estos filmes, normalmente, no por lo que tienen de histórico - de recreación o explicación del pasado- e instructivo, sino porque son un medio de entretenimiento" (Montero, 2001: 33).

30 "El cine contribuye a la elaboración de una contra-historia no oficial, alejada de esos archivos escritos que muchas veces no son la memoria conservada de nuestras instituciones" (Ferro, 1995: 17).

${ }^{31}$ Como señala Montero (2001: 51) "lo fundamental es que el historiador explica procesos generales mediante conjuntos de causas que actúan de manera diversa en momentos distintos. Y eso incluso cuando hace biografías. El cineasta sigue justamente el camino contrario: la vida -a veces inventada- de un reducido número de personas, da cuenta explicativa de procesos complejos, con una simplicidad que difícilmente aceptará un investigador social. Si hubiera que resumir esta idea podría decirse que el realizador de películas históricas explica el pasado desde la sicología del sentido común y el historiador lo hace desde la compleja trama de las ciencias sociales".

32 "El film se observa no como obra de arte, sino como un producto, una imagen objeto cuya significación va más allá de lo puramente cinematográfico; no cuenta sólo por aquello que atestigua, sino por el acercamiento socio-histórico que permite. Así que explica que el análisis no considere necesariamente al conjunto de la obra, sino que pueda basarse en fragmentos, examinar "series", establecer relaciones. La crítica tampoco se limita al film, sino que se integra a todo el mundo que le rodea y con el que está necesariamente comunicado. En estas condiciones no basta con emprender análisis de films, trozos de films, planos, argumentos, etc., recurriendo según las necesidades a los conocimientos y vías de abordaje de las diferentes ciencias humanas. Es necesario aplicar estos métodos a cada elemento del film (imágenes, imágenes sonoras, imágenes silenciosas), a las relaciones entre los componentes de esos elementos; analizar en el film tanto la intriga, el decorado, la planificación, como las relaciones del film con lo que no es el film: la producción, el público, la crítica, el sistema político. De este modo podemos esperar comprender no sólo la obra, sino también la realidad que representa" (Ferro, 1995: 39). 
33 “Desde el punto de vista del historiador no se puede extraer el contenido y el significado histórico de un film estudiándolo de forma aislada, porque no hay ningún contenido independiente de su contexto. Para nuestro propósito, en lo que el film transmite se ha de incluir el mensaje connotativo que tiene, tuvo o pudo tener -consciente o inconsciente- para quienes lo realizaron y para aquellos que lo vieron. El contenido y el significado nada más pueden ser definidos con relación a un emisor y a un receptor del mensaje que se transmite, e incide en el contexto, en la sociedad" (Caparrós, 1997: 24). 